\section{ASSOCIATION BETWEEN UNDIAGNOSED SLEEP DISORDERS AND CARDIOVASCULAR DISEASE IN HEALTHY TRUCK DRIVERS}

${ }^{1}$ Nicola Magnavita*, ${ }^{2}$ Alicja Bortkiewicz, ${ }^{3}$ Paolo Durando, ${ }^{3,4}$ Sergio Garbarino. ${ }^{1}$ Institute of Public Health, Università Cattolica del Sacro Cuore, Rome, Italy; ${ }^{2}$ Nofer Institute of Occupational Medicine, Department of Work Physiology and Ergonomics, kódź, Poland; ${ }^{3}$ Department of Health Sciences, University of Genoa, Genoa, Italy; ${ }^{4}$ Department of Neuroscience, Rehabilitation, Ophthalmology, Genetics and Maternal/Child Sciences (DINOGMI), University of Genoa, Genoa, Italy

\subsection{6/oemed-2018-ICOHabstracts.179}

Introduction Sleep disorders (SD), including obstructive sleep apnea (OSA), sleep loss, and insomnia are highly prevalent and underdiagnosed conditions that have negative impacts on quality of life, mood, cognitive function, and cardiovascular disease (CVD). The aim of the study was to explore the prevalence and the relationship between SD and CVD in healthy truck drivers with undiagnosed and untreated sleep disorders. Methods Trained medical staff offered a free medical examination to truck drivers parked in some of the major Italian trucking hubs. The study enrolled 949 truck drivers. The prevalence of SD and CVD was clinically assessed.

Results 177 truck drivers (18.7\%) had CVD. Multivariate logistic regression showed that SD are significant predictors of CVD. Drivers with OSA had a more than three-fold increased risk of CVD (OR 3.41, 95\% CI: 2.30 to 5.04). Insomniac drivers had an increased risk of CVD (OR 1.54 95\% CI: 1.00 to 2.31). Age and obesity (body mass index, BMI) were also associated with increased odds for CVD. Sleep loss, and short sleep duration, were not independently associated with CVD in the multivariate model.

Discussion Evidence suggests that obstructive sleep apnea (OSA) is related to cardiovascular disease. Insomnia can also be associated with CVD, even if the association is less evident. Sleep is increasingly recognised as an important lifestyle contributor to health.

\section{EYE-TRACKING AS A METHOD FOR EVALUATION OF THE DRIVER'S VISUAL STRATEGY}

M Kosobudzki* , E Gadzicka, J Siedlecka, M Dania, W Szymczak, Z Jozwiak, A Szyjkowska, P Viebig, A Pas-Wyroślak, T Makowiec-Dąbrowska, B Kapitaniak, A Bortkiewicz. Nofer Institute of Occupational Medicine, Lodz, Poland

\subsection{6/oemed-2018-ICOHabstracts. 180}

Introduction One of the most important parameters of interest in the study of drivers on the driving simulator is the oculometric data obtained during driving. Using this method we have a direct view of the driver's eye path and ability to analyse it. The purpose of the study was to trace the places where the driver's eyes focus when driving on a bus simulator.

Materials and methods The study was conducted in a group of randomly selected 45 city bus drivers. Thanks to the use of appropriate infrared cameras, scene cameras and specialised software, data has been obtained and selected using special programs and statistical analysis. By collecting this data we are able to analyse the driver's eye-path in different situations on the road (urban driving, off-road driving, and stress-based driving).
Methods FaceLab was used to track the visual path with infrared cameras. We also use scene cameras and Eyeworks (Record, Analyse) and Captive programs. These programs enabled the visual path to be taken in the form of saccades and fixations applied to a video file with recorded driving data and data from the simulator. Then the image from the scene camera (what the driver saw) was divided into regions (areas in front of the driver's eye or side mirror surfaces) so it was possible to analyse the individual regions of all the drivers taking part in the experiment.

Results The driver during $28.77 \%$ of the driving time on the simulator focused on the area of the road directly in front of the vehicle and on the right-hand mirror it was $2.27 \%$ of the driving time.

Discussions The obtained data confirm that the driver is most likely to look at the road ahead and the area surrounding the right mirror (which is affected by stops at the bus stops).

\section{FACILITATING RETURN TO WORK AND MAINTENANCE OF EMPLOYMENT AFTER MYOCARDIAL INFARCTION: RESULTS OF A RANDOMISED TRIAL}

${ }^{1,2}$ Shlomo Moshe, 2,3 Oren Zack. 'Maccabi Healthcare Senvices, Occupational Department, Holon, Israel; ${ }^{2}$ Sackler Faculty of Medicine, School of Public Health, Division of Environmental and Occupational Medicine, Tel-Aviv University. Tel-Aviv, Israel; ${ }^{3}$ Israel Defence Force Medical Force, Ramat Gan, Israel

\subsection{6/oemed-2018-ICOHabstracts.181}

Introduction Cardiovascular disease is the most prevalent of lifethreatening disorders in industrialised countries and is a rapidly growing problem in developing nations. Cardiac rehabilitation has been shown to reduce morbidity and mortality. One of the significant markers of recovery and an essential element in the overall well-being is the return-to-work (RTW) of cardiac patients.

Methods In this randomised trial which spanned 2 years of follow-up, we studied 151 cardiac patients under the age of 57 who had undergone acute myocardial infarction and that had been working for at least 1 year prior to the event. Patient data was collected on three main elements: 1. Demographic, 2. Psychological and 3. Occupational parameters. Following an examination by a cardiologist, patients were randomised into intervention $(n=74)$ and control $(n=77)$ groups. The control group received the currently acceptable rehab program. The study group received rehabilitation program by a case manager.

Results The study group had a significantly higher rate of RTW within 6 months than the control group (89\% vs 74\% respectively, $\mathrm{p}<0.05)$. A significantly higher return to a full-time job (80\% vs $63 \%, \mathrm{p}<0.05)$ and same position/role $(98 \%$ vs $73 \%, \mathrm{p}<0.001)$ was seen in the study vs the control group respectively. The study group exhibited a significantly higher job persistency rate compared to the control group ( $88 \%$ vs $72 \%$ respectively, $\mathrm{p}<0.05$ ).

Conclusions This study presents a novel approach for facilitating RTW and rehabilitation of cardiac patients utilising the services of occupational medicine clinics and social workers therein. The studied approach proved highly efficient with higher RTW and higher job persistency rates. We recommend the assimilation of our approach in all clinics engaging in the active rehab of cardiac patients and in the support of patient recovery and overall wellbeing. 